\title{
Growth rate of primary left atrial myxoma
}

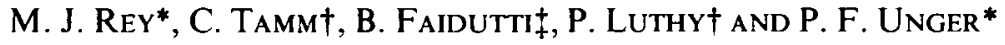 \\ From ${ }^{*}$ Emergency Center, $†$ Cardiologic Center and $\ddagger$ Cardiovascular Surgery Clinic, University Hospital of Geneva, \\ Geneva, Switzerland
}

KEY WORDS: Atrial myxoma, tumour growth rate.

We describe the growth of a primary left atrial myxoma over a period of approximately 27 months, review the literature on the growth rate of primary myxoma and discuss the value of echocardiography compared to CT scan and MRI in the diagnosis of intracardiac tumuors.

\section{Introduction}

The growth rate of primary cardiac myxoma can rarely be established because of the lack of specific symptoms before the tumour has reached a certain size ${ }^{[1]}$.

We report a case of left atrial myxoma discovered 27 months after an echocardiogram had showed normal cardiac chambers; we discuss the growth rate of this benign tumour and review the literature on the growth rate of primary myxoma.

A woman, born in 1918, was hospitalized in February 1992 after several falls without loss of consciousness during the preceding days. She had been treated for heart failure and hypertension in December 1989. A transthoracic echocardiogram performed at that time had shown mitral valve prolapse and moderate mitral regurgitation, confirming the auscultation of a decreased first heart sound with a holosystolic murmur, maximal at the heart apex (Fig. 1(a)).

On admission, she was sub-febrile. Her blood pressure was $150 / 190 \mathrm{~mm} \mathrm{Hg}$ and pulse regular at 100 beats. $\mathrm{min}^{-1}$. The first heart sound was louder than the second, and a systolic murmur was heard along the right sternal border; there was no opening snap or diastolic rumble. There were no signs of right heart failure. The respiratory rate was $20 \mathrm{~min}$ ' and there were slight crackles at both lung bases. Because the cardiac ausculation was different from that described in December 1989, a transthoracic echocardiogram was performed. This second echocardiogram showed a left atrial myxoma prolapsing through the mitral valve during diastole and tricuspid regurgitation (Fig. 1(b)). On the following day, the myxoma attached at the fossa ovalis was resected without complication. The myxoma weighed $42 \mathrm{~g}$ and measured $4.5 \times 2.9 \times 3.9 \mathrm{~cm}$.

\section{Discussion}

Histologically, myxomas consist of an acid mucopolysacharide matrix containing polygonal cells and occasional blood vessels. Although recurrent myxomas

Submitted for publication on 24 A ugust 1992. and in revised form 22 February 1993.

Correspondence Mane J Rey, MD. Medical Clinic. University Hospital of Geneva, 24 rue Micheli-du-Crest, 1211 Geneva 4. Swıtzerland. have been described after resection, such occurrences have been explained by incomplete resection or multifocal growth, and the malignant nature of the tumour has never been ascertained ${ }^{[2]}$. The Mayo clinic group ${ }^{[3]}$ described the cytogenetic characteristics of myxomas and demonstrated chromosomally abnormal clones and non-random telometric translocations without finding criteria for a true neoplastic disease.

Few reports of growth of primary myxoma have been published. Marinissen et al ${ }^{[4]}$ reported the resection of a left atrial myxoma of $6 \times 4 \mathrm{~cm} 18$ months after the patient had had an aortocoronary bypass graft and a normal Mmode echocardiogram of the left atrium. Roudaut $\mathrm{et} \mathrm{al} .^{[5]}$ reported the resection of a myxoma of approximately $5.5 \times 4 \mathrm{~cm}$, which had grown over 7 months following a control angiography after a coronary bypass operation.

In our patient, the growth rate of the primary myxoma can be only approximate as growth may have started at any point between the first and the second transthoracic echocardiogram. If we take 27 months as the maximum possible period of growth, the growth rate compares with the figure cited for recurrent myxomas ${ }^{[6]}$, i.e. $1.5 \mathrm{~g}$ per month. The fact that the growth rate of primary myxoma is the same as that in those that recur would support further the non-malignant nature of the tumour.

Transthoracic echocardiography is the preferred diagnostic tool for the detection of intracardiac tumours because of good contrast between tumour and echolucent chamber cavity and its ease of obtention; the value of this technique has improved with the transoesophageal approach which provides higher quality images especially of the right atrium and interatrial septum ${ }^{[]}$. Other techniques used to detect intracardiac tumours, such as computed tomography $(\mathrm{CT})^{[8]}$, cine-computedtomography or magnetic resonance imaging (MRI) ${ }^{19]}$ are more useful in that they provide information on the site of attachement of the tumour to the wall of the cardiac chamber, or to differentiate a tumour from a thrombus by the tissue characterization ${ }^{[10]}$. Compared to CT, MRI has the ability to generate images in multiple planes, a feature that will also be available soon with multiplane transoesophageal echocardiography. This last technique will have the advantage of its easy availability and lower cost, compared to MRI, but will still lack tissue characterization. 


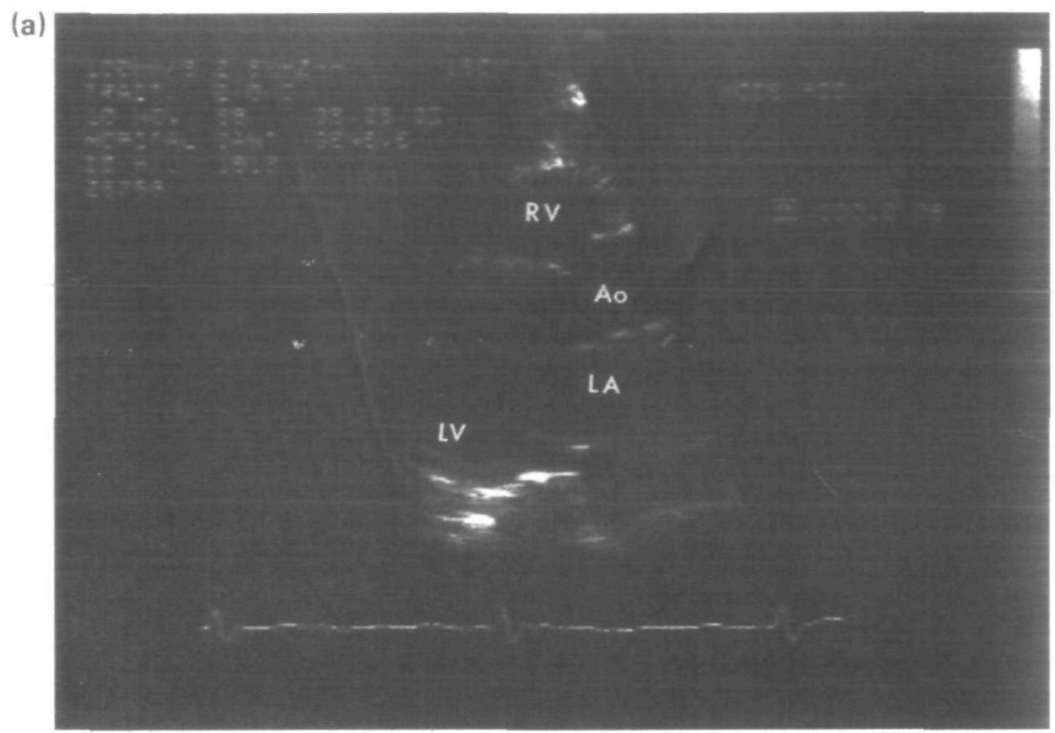

(b)

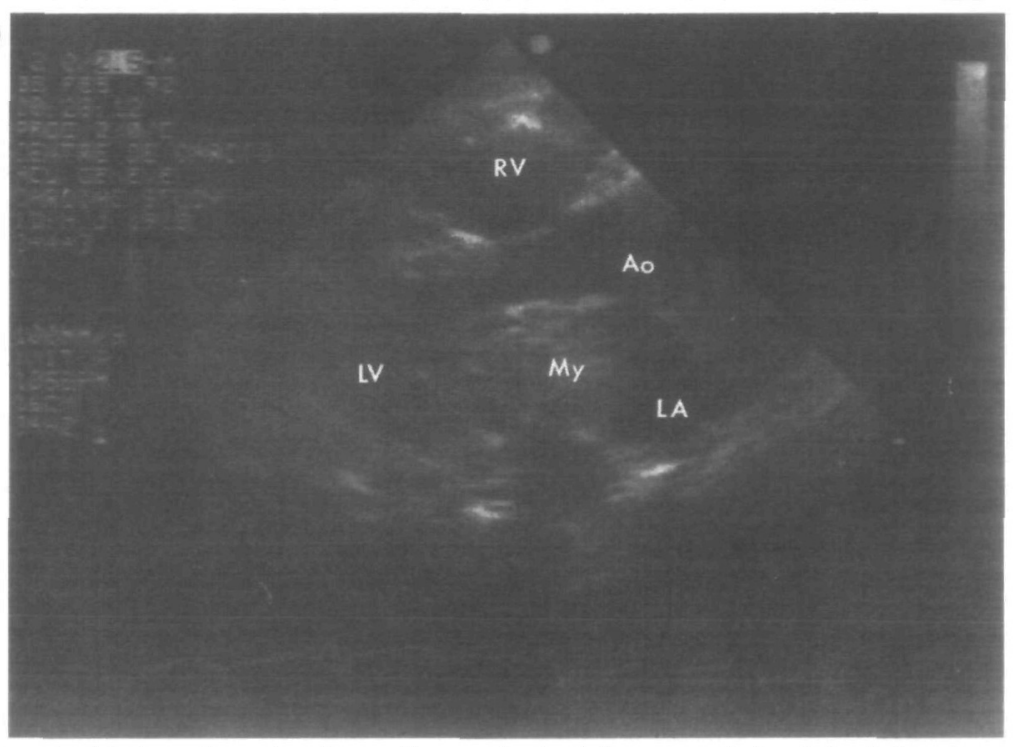

Figure 1 (a) Transthoracic echocardiogram in the left pasternal view $L A=$ left atrium; $\mathrm{LV}=$ left ventricle; $\mathrm{AO}=$ aorta; $\mathrm{RV}=$ right ventricle. (b) Transthoracic echocardiogram in the left parasternal view. Abbreviations are the same as in Fig. I(a). My=myxoma.

With the increased use of transthoracic and transoesophageal echocardiography, and other cardiac imaging techniques more myxomas will be discovered on repeat examination, allowing a more accute estimation of their growth.

We thank Dr L. A. Mercier, Montreal Heart Institut, Montreal Canada, for her review of this manuscript.

\section{References}

[1] Sutton St. JM, Mercier LA, Guiliani E, Lie JT. Atrial myxoma. Mayo Clin Proc 1980; 55: 371-6.

[2] Salcedo EE, Cohen GI, White R, Davidson MB. Cardiac tumours: diagnosis and management. Curr Probl Cardiol 1992; 2: $105-12$.

[3] Dewald GW, Dahl RJ, Spurbeck JL, Carney JA. Chromosomally abnormal clones and nonrandom telometric translocations in cardiac myxomas. Mayo Clin Proc 1987; 62: 558-67.
[4] Marinissen KI, Essed C. de Groot C. Schelling A. Growth rate of left atrial myxoma. Development of a symptomatic left atrial myxoma less than two years after coronary artery bypass grafting. Chest 1987; 5: 941-2.

[5] Roudaut R, Gosse Ph, Dallochio M. Rapid growth of a left atrial myxoma shown by echocardiography. Br Heart $\mathrm{J}$ 1987; 58: 413-6.

[6] Malekzadeh S, Roberts WC. Growth rate of left atrial myxoma. Am J Cardiol 1989; 64: 1075-6.

[7] Pavlides GS, Hauser AM, Stewart JR et al. Contribution of transesophageal echocardiography to patient diagnosis and treatment: a prospective analysis. Am Heart J 1990; 120:910-4.

[8] Kawai N, Iwase M, Yokota $M$ et al. Evaulation of left atrial myxoma with transmission computed tomography. Am Heart J 1985; 109: 1116-9.

[9] Sechtem U, Pflugfelder PW, White RDet al. Cine MR imaging: potential for the evaluation of cardiac function. Am J Roentgenol 1987; 148: 239-46.

[10] Tomoda H, Hoshaiai M, Furuya $\mathrm{H}$ et al. Evaluation of left ventricular thrombus with computed tomography. Am J Cardiol $1981 ; 48 ; 573-7$. 